\title{
Situated learning through intergenerational play between older adults and undergraduates
}

Fan Zhang*(D), David Kaufman, Robyn Schell, Glaucia Salgado, Erik Tiong Wee Seah and Julija Jeremic

\author{
*Correspondence: fza26@sfu.ca \\ Faculty of Education, Simon Fraser \\ University, Burnaby, BC, Canada
}

\begin{abstract}
This study is grounded in a social-cultural framework that embeds learning in social activities, mediated by cultural tools and occurring through guided participation in the social practice of a particular community. It uses conversation analysis as a tool to examine the structures of the talk-in-interaction of naturally occurring conversations between 11 pairs of older adult (aged between 65 and 92) and undergraduates (aged between 18 and 25) during a 6-week social practice of intergenerational digital gameplay. The purpose is to demonstrate how older adults adapt to and make sense of collaborative gaming activities through guided participation. The features of minimum gap and overlap, even conversational inputs, and orientation to one another's turns indicate interactional connection between older adults and younger people. Adjacency pairs in the form of question-answer and self-initiated other-repairs are the situated use of social resources afforded by the intergenerational interaction. It is through these two main means of interaction that younger players offer immediate feedback and explanation to guide older adults to engage in the collaborative play and develop understanding of unfolding concepts and phenomena.
\end{abstract}

Keywords: Situated learning, Intergenerational play, Digital games, Conversation analysis

\section{Introduction}

Intergenerational interactions can exhibit positive effects on both older adults and younger people (Chua, Jung, Lwin, \& Theng, 2013). Digital games are symbolic and cultural tools that promote meaningful interactions, and collaborative play provides a rich social context for guided participation (Piirainen-Marsh, 2010). The purpose of the current study is to investigate how intergenerational digital gameplay facilitates situated learning between older adults and younger people. In the following sections, we first describe learning in later life, the concept of situated learning, situated learning in social gameplay, the importance of meaningful intergenerational play, and specific research questions. We then describe the design of a 6-week social practice of intergenerational digital gameplay between 11 pairs of older adults (aged 65-92) and undergraduates (aged 18-25), and present the results based on the conventions of conversation analysis. Finally, we conclude with a discussion of our findings.

(c) The Author(s). 2017 Open Access This article is distributed under the terms of the Creative Commons Attribution 4.0 International License (http://creativecommons.org/licenses/by/4.0/), which permits unrestricted use, distribution, and reproduction in any medium provided you give appropriate credit to the original author(s) and the source, provide a link to the Creative Commons license, and indicate if changes were made. 


\section{Learning in later life}

The population all over the world is ageing (Manchester \& Facer, 2015). The number of people aged 60 years and over in the world is predicted to grow by $56 \%$ between 2015 and 2030, and by 2050, the world's older population is projected to double its size in 2015 (United Nations, 2015). In general, society has a relatively negative attitude towards older adults (Hernandez \& Gonzalez, 2008). The findings of a previous metaanalytic study indicated that attitudes were more negative toward older than younger adults although perceptions of older adults are multidimensional (Kite, Stockdale, Whitley, \& Johnson, 2005). Older adults are stereotypically seen as unfit for learning activities due to declining intelligence, memory, and sensory abilities (Chang \& Lin, 2011). Consistent with the cognitive view of age-related differences in learning, research has shown a negative correlation between age and learning performance (Kubeck, Del, Haslet, \& McDaniel, 1996; Ng \& Feldman, 2008). Jeske and Rosnagel (2015) criticized these laboratory studies for using well-established frameworks from cognitive psychology that require participants to work with novel learning materials. However, real-life learning allows older learners to draw on prior knowledge, expertise, motivation, and strategies, which are products of life experience (Jeske \& Rosnagel, 2015). Chang and Lin (2011) highlighted that older adults are capable of learning. Research has suggested that lifelong learning is tightly associated with sustained cognitive function (Rowe \& Kahn, 1998; Schaie, 1994), as well as continued and extended social interaction (Withnall, 2010).

\section{Sociocultural theory and situated learning}

Sociocultural theory stresses how participation in social interactions and culturally organized activities influences the processes of thinking and learning (Black \& Reich, 2011). Social interaction is mediated by tools and signs (e.g., language, algebraic symbol systems, writing) and other semiotic means, such as computers and calculators (Wertsch, 1991). A core concept of sociocultural theory is that learning occurs through guided participation in a range of joint activities to co-construct and internalize knowledge. This type of supported learning is described in terms of the concept of the zone of proximal development (ZPD), which is defined as "the distance between the actual developmental level as determined by independent problem solving and the level of potential development as determined through problem solving under adult guidance, or in collaboration with more capable peers" (Vygotsky, 1978, p.86). Rogoff (1990) states, "children's cognitive development is an apprenticeship - it occurs through guided participation in social activity with companions who support and stretch children's understanding of and skill in using the tools of the culture" (p.vii).

From the sociocultural perspective, learning is embedded in the fabric of social activities in which novice learners, supported by expert learners, gradually develop the ability to achieve goals and solve problems without help (Vygotsky, 1978). In this vein, the expert other "structures the learning experience and provides incremental guidance to support the novice's success at a given task" (Reich, Korobkova, Black, \& Sumaroka, 2013, p.4). Gee (2008) highlighted that social identity is crucial to learning; goals, ways of functioning, interpretation and assessment, and types of feedback reflect the values, established practices, knowledge, and skills of an experienced member of a social group. Situated 
learning focuses on the social and cultural origins of cognition, which is situated and distributed in the environment (Brown, Collins, \& Duguid, 1989). In situated cognition, learners carry on activity in the world, adapted to the constraints and affordances of the environment (Bereiter, 1997). Situated learning is primarily a social- cultural process. It is a matter of connection one builds with communities-first as a legitimately peripheral participant, but gradually as a full participant (Lave \& Wenger, 1991).

\section{Situated learning through collaborative gameplay}

Digital games are hypothesized to affect learning in two ways: providing intrinsic motivation and changing cognitive processes (Wouters, van Nimwegen, van Oostendorp, \& van der Spek, 2013). Games include important factors that intrinsically motivate players to engage in appealing activities to help them learn, including challenge, curiosity, and fantasy (Malone, 1981; Malone \& Lepper, 1987). Factors such as autonomy and competence also contribute to a moment-to-moment experience that is inherently enjoyable and appealing (Wouters et al., 2013). Previous studies have examined the social context of gameplay based on sociocultural theory. Collaborative play creates a natural social context for guided participation in which more experienced players provide incremental guidance to support the success of less experienced players at a given task (Reich et al., 2013). Black and Reich (2011) explored how the content and design of the virtual world Weblinz World served as a sociocultural context and support for informal learning. Reich et al. (2013) conducted a qualitative study to understand children's digital game use within the context of their daily lives and how it relates to family connections. Their findings showed that the older sibling served as the more capable other, supporting their younger siblings' gameplay through explicit scaffolding. PiirainenMarsh and Tainio (2009) examined how a collaborative gaming activity creates opportunities for situated use of language resources. The findings revealed that players' ongoing participation in the unfolding circumstances of Final Fantasy X (a role-playing game), and their interpretation of the scenes and events in the game, offer rich resources for situated learning of a second language.

\section{Intergenerational digital gameplay}

There has been increasing research about intergenerational interaction as intergenerational separation has become a social issue in industrialized societies (Kaplan, Sanchez, Shelton, \& Bradley, 2013; Vanderbeck, 2007). Previous research has shown intergenerational interaction generates positive affect, self-esteem, and life satisfaction among older adults (Kessler \& Staudinger, 2007), and improves older adults' memory and positive mood (Newman, Karip, \& Faux, 1995). This is especially the case when older adults' role as teachers, advice givers, and conveyors of experience is supported and enhanced through meaningful intergenerational exchanges (Kessler \& Staudinger, 2007). Participation in intergenerational programs can reduce adolescents' negative age stereotypes (Fox \& Giles, 1993) and change their negative attitude towards older adults (Hernandez \& Gonzalez, 2008). However, it is a challenge to engage the two age groups in reciprocal interactions and sustain the long-term interest of younger people in intergenerational programs (Harley, Vetere, Fitzpatrick, \& Kurniawan, 2012). 
Play is an activity "mediated by tools and artifacts as well as symbolic systems such as language" (Black \& Reich, 2011, p.53). It is also a common means for grandparents and grandchildren to build relationships, enjoy each other's company, learn together, resolve problems collaboratively, and get close through mutual encouragement (Zhang \& Kaufman, 2016a). Today, many younger people and older adults have integrated digital games into their daily leisure activities (De Schutter \& Malliet, 2014). In 2015, 26\% of game players in America were aged 50 and over (ESA, 2016). Kun (2015) recruited 354 older adults who played World of Warcraft (an online digital game) through a Web survey, and $6.2 \%$ of respondents were in the age group of 80 and older. Intergenerational digital gameplay creates a natural context for common goals, cooperation, and equal status that are key factors for intergenerational interaction (Chua et al., 2013). Zhang and Kaufman's (2016a) review study identified 11 digital games developed to facilitate intergenerational interaction and learning, such as Distributed Hide-and-Seek (Vetere, Nolan, \& Raman, 2006), Curball (Kern, Stringer, Fitzpatrick, \& Schmidt, 2006), TranseCare (Derboven, Van Gils, \& De Grooff, 2011), Age Invaders (Khoo, Cheok, Nguyen, \& Pan, 2008), etc. Digital games can transcend the dimensions of time, space, and close personal relationships and allow players to practice intergenerational skills in a safe environment (Ypsilanti et al., 2014). In addition, there are tremendous empirical findings showing that playing digital games can improve older adults' physical and cognitive function (Zhang \& Kaufman, 2016b) and enhance the quality of their socio-emotional life (Schell, Hausknecht, Zhang, \& Kaufman, 2016; Zhang \& Kaufman, 2015).

\section{Research questions}

In recent years, there has been increasing attention on the potential of digital games to facilitate intergenerational interactions (Kaplan et al., 2013). Chua et al.'s (2013) study found that in these interactions, younger people are more likely to be the technology experts and teach technical knowledge to older generations. However, Kaplan et al. (2013) highlighted that the intergenerational communication dynamic becomes multi-directional as older adults become more knowledgeable about technology and more comfortable sharing experiences and learning from and with younger generations. Voida and Greenberg (2012) examined the intergenerational gaming practices of four generations of console gamers at collocated environments. Their findings revealed that both young and adult gamers took on the teacher's role during intergenerational play; however, the group play in this study lasted a short time (an hour and $15 \mathrm{~min}$, on average). These inconsistent findings emphasize the need for more research studies with rigorous study design and data analysis methods. If the primary goal of intergenerational programs is to encourage knowledge transfer mediated by social interaction, it is important to understand how digital games facilitate conversation, communication and learning between the two age groups, and how the age differences could be used to sustain mutual engagement in the games (Zhang \& Kaufman, 2016a). The specific research questions of the current study include:

1. How do older adults develop game knowledge and become members of game communities?

2. What are the patterns of social interaction that facilitate situated learning between older adults and younger people? 


\section{Methodology}

The data were collected from 6-weeks of collaborative play that took place among 11 intergenerational pairs in senior and community centres in Greater Vancouver. Each intergenerational pair consisted of one older adult (aged between 65 and 92) and one undergraduate (aged between 18 and 25). The two participants of each pair did not know each other before this study, and were paired based on the match of their schedule. The two players sat side by side and played two Wii Sports Resort games (i.e., Cycling and Canoeing) for 2 weeks each (45 min per week). This was followed by playing both games again in the last 2 weeks in order to experience playing together at a higher level after both players had improved their skills.

The Wii Cycling race starts with the player in last place, with the goal of overtaking cyclists in front of the player to make it to first position. The object of Wii Canoeing is to reach an increasingly distant finish line within a time limit by overcoming obstacles (e.g., floating objects and grass) and water-disturbing objects (e.g., big fish and water spouts). These two games are simple to play, but they require the two players to coordinate and communicate with each other in order to win by overcoming the obstacles. All participants were new to the two Wii games before this study, but the younger participants played other digital games at least once a week and were therefore viewed as more experienced players who would guide or coach the older participants. During the collaborative play, the participants drew upon the semiotic and material structure of the games to negotiate available choices or comment on emerging scenes and actions. This unfolded mainly through conversations.

Participants' conversations were analyzed following the conventions of conversation analysis (Appendix A) established by Jefferson (2004), which focuses on the turn-byturn unfolding of talk-in-interaction in everyday situations. The features of talk-ininteraction organization frame the basic work of conversation analysts (Chepinchikj \& Thompson, 2016). Turn-taking, the fundamental organization of talk-in-interaction, is sequential organization of talk in conversation, in which one person speaks at a time in alternating turns. The turns consist of turn construction units (TCUs), which can vary from single lexical items (e.g., "thanks" and "yes") to larger constructs, such as clauses and sentences (Chepinchikj \& Thompson, 2016). The TCUs can project the possible directions and completions of utterances (Padilha, 2006). The next speaker can either self-select or be selected by the current speaker. Adjacency pairs are sequences of paired actions, such as question-answer, proposal-evaluation, greeting-greeting, offeracceptance (or declining), etc. They are normatively structured into pairs, and participants orient themselves accordingly. Repairs refer to a period of talk in which miscommunication occurs, is noted, and is resolved (Lind, Okell, \& Golab, 2009). The mechanism of repair consists of the three dimensions of "repair trajectory": trouble source, repair initiation, and repair execution (Fereneík, 2005).

Good learning requires participation in social groups that help learners understand the learning goals and make sense of their experience through interpretation, practice, explanation, debriefing, and feedback (Gee, 2008). In the following section, specific excerpts will be presented to illustrate how intergenerational play offers social and cultural resources upon which older adults can draw to develop expertise as members of the community and co-construct meaningful gaming activities. Although the selected excerpts cannot depict the whole picture of intergenerational play, they can shed light 
on the patterns of intergenerational interactions and affordances for learning that arise in the course of collaborative play. The primary selecting criterion is whether the two age groups engage in interactional social activities and orient to each other, which is the premise of the occurrence of situated learning. In the following example, the two players talk with each other, but do not engage in one another's turn. See Appendix A for a list of the notational symbols used in the analysis.

\section{Example 1}

$\mathrm{O}=$ Older Player; $\mathrm{Y}=$ Younger Player

1 O: Let's go back to (0.2) expert and then 100 yards

2 because on the competition we are only doing 100 yards.

3 Y: Oh, ok.

4 O: >Right, right, right, right.<

5 Y: Oh, sorry.

6 O: Right now there you go.

7 Y: That's it.

\section{Analysis}

Learning to Co-participate by asking questions and receiving feedback

Example 2 comes from the beginning of the first game session. The basic activity is to select in-game avatars. In line 1 , the younger player initiates the notification of selecting their avatars. Then, the older player asks the younger player to confirm her avatar. The younger player says she can select any one and displays to her the action of selecting an avatar, which indicates that the older player has no idea about character selection and is a novice player. The older player's first turn ("This is me?") is the first pair part (FPP) of an adjacency pair. The younger player's answer (line 3 ) is the second pair part (SPP) of the adjacency pair and addresses the older player's question. Then, the older player initiates another round of question-answer sequence in order to figure out which button she should press (lines 5-6).

\section{Example 2}

$\mathrm{O}=$ Older Player; $\mathrm{Y}=$ Younger Player

1 Y: Okay. Now we just have to select our people

2 O: This is me?

3 Y: Ye:ah. You can select whichever one you want. You just have to get your 4 right hand here.

5 O: $\uparrow$ A?

$6 \mathrm{Y}$ : We have to see the right hand on the screen.

7 O: Okay.

8 Y: See if it comes up. Try pointing it towards this.

9 O: $\uparrow$ Oh:, here, not there.

10 Y: Do you see your little right hand up there?

11 O: Yes.

$12 \mathrm{Y}$ : So, you get it on your drill and press A.

13 O: $>\uparrow$ Wait, $\uparrow$ wait. $<$ Where did I get it? = Did I get it? 
14 Y: No.

15 O: I don't think so. It was $\uparrow$ to:o fast.

16 Y: Okay, there is mine. There. You can try again.

17 O: It moves fast.

18 Y: Try. Oh, that is mine. Yours is the red one. So, try. Oh, there it is.

19 O: $\uparrow$ Did I get it?

20 Y: No. You have to hit A. I think you are hitting B, $\uparrow$ Right?

21 O: $\uparrow$ Oh::. Yes, I am.

22 Y: Okay. So, you just press this one when you are on $\uparrow$ her and then you will get it.

$23 \mathrm{O}$ : I am not touching anything. I am just ${ }^{\circ}$ trying to ${ }^{\circ}$.

24 Y: So, this hand down here, on her face, and then when you are on her, $\uparrow$ hit $\uparrow \mathrm{A}$.

$25 \uparrow$ Per::fect.

Although the older player understands the mechanisms of character selection, she is still unable to complete it successfully. In line 8 , the younger player helps the older player resolve the problem by directing her to try a possible solution. The older player's response (“ $\uparrow \mathrm{Oh}$ :, here, not there") indicates she realizes where she went wrong. In lines 10-11, the younger player directs the older player's attention to the "little right hand" on the screen by formulating a question to check whether she sees it. The older player's response ("Yes") is a preferred answer. This question-answer sequence initiated by the younger player serves a different purpose from the question-answer sequence initiated by the older player. The first aims to ensure the older player is ready for next step, while the latter is a direct instruction from the younger player.

In line 12, the younger player is teaching the older player to "press A" button. The older player's repeated and speeded-up words ("> $>$ Wait, $\uparrow$ wait, $<$ ") are delivered with raised pitch, which interrupts the instruction. The older player continues her turn by asking two questions without a gap (line 13). The younger player's short and negative answer ("No") indicates that she does not know why the older player failed, because selecting an avatar is simple (just press the 'A' button when the "right-hand" is on the face of the avatar). The younger player's negative response is consistent with the older player's next turn ("I don't think so") and also makes the older player realize it is difficult for her to control the "right-hand" because it moves " $\uparrow$ to:o fast". In lines 16-18, the younger player is mentoring the older player to try the actions once again. In line 19, the older player is asking the younger player whether she successfully selected the avatar, which is the FPP of a question-answer sequence. Although the SPP starts with a negative word ("No"), it is a preferred turn because the younger player produces a possible reason for the older player's failure ("You have to hit A. I think you are hitting B, $\uparrow$ Right"). The older player delivers her next turn with markedly raised pitch (“^Oh::”), displaying she knew where she went wrong and also indicating that the SPP is a preferred turn.

After correcting the older player's mistake, the younger player starts another round of instruction (line 22). The older player's emotional response ("I am not touching anything. I am just "trying to") indicates the third failure. She stresses she hasn't touched any button, displaying that she seems to be nervous as she needs to control the "righthand" and at the same time press the 'A' rather than 'B' button. The younger player says "So" to start the fourth round of instruction. To help the older player overcome the game's physical challenges, this time the younger player changes the teaching technique, dividing the task into small steps, coaching the older player step by step and 
reminding her to press ' $\mathrm{A}$ ' button by clearly verbalizing it with raised pitch (“ $\uparrow$ hit $\uparrow A$ "). " $\uparrow$ Per::fect." expresses the younger player's enjoyment and excitement and positive evaluation of the older player's successful action after the four-round instruction.

Example 3 comes from the end of a new game task. In line 1, the older player is asking, "How come we are coming down again?", which is the FPP of a question-answer sequence. The SPP starts with the younger player's explanation of the possible reason. She says it is the "hill on the course" and "wind" making them come down. At this point it is unclear whether this is a satisfactory answer because her next utterance, "^Wow:", signifies the closure of this sequence. In line 4, the younger player starts a new sequence by commenting on the unfolding scenes in the game and excitedly announcing their "^awe:some" game performance. The older player's minimal response (" $£ O h: €$ "), on the other hand, shows she hasn't realized what was going on. After receiving the older player's minimal response, the younger player further explains why they worked well ("I think that is our best ever") and specifically comments on the older player's good actions ("You went $\uparrow$ really fa:st"). In response to a preferred assessment, the older player produces a preferred turn, "That is good for a first try:". Then, she asks, "I could not understand. We were on $29^{\text {th }}$ and we were coming down. I wonder what that means". This question is the same as the one asked in the first sequence, showing that the younger player misunderstood the meaning of the question the first time. ' $29^{\text {th }}$ refers to their position compared to other in-game competitors. Based on this clue, the younger player reformulates the question and checks with the older player, "Like our place was coming down?" After understanding the older player's question, the younger player explains, "Oh:, people were passing us. We were falling behind". The older player repeats the younger player's utterance, but does not indicate whether she understands it (line 13). So, the younger player further explains there are other competitors in the game whom are not shown on the screen. It is at this point where the older player confirms her understanding of the meaning (line 17).

\section{Example 3}

$\mathrm{O}=$ Older Player; $\mathrm{Y}=$ Younger Player

1 O: How come we are coming down again?

2 Y: I don't know. I think it is just the hill on the course.

3 We have got the wind pushing us.

$4 \uparrow W o: w$, we $\uparrow$ did $\uparrow$ awe:some. We came on $10^{\text {th }}$.

5 O: $£ \mathrm{Oh}: £$

$6 \mathrm{Y}: £ \mathrm{I}$ think that is our best ever. You went $\uparrow$ really fa:st.

7 That was awe:some! $€$

8 O: That is good for a first try::. I could not understand.

9 We were on $29^{\text {th }}$ and we were coming down. I wonder what that means.

10 Y: Like our place was coming down?

11 O: Ye:ah.

12 Y: Oh:, people were passing us. We were falling behind.

13 O: Oh::, we were right behind.

14 Y: Yeah. ${ }^{\circ}$ Because they have ${ }^{\circ}$ You cannot really see them.

15 But some of the character are like right behind you and 
16 if you start coming back, they push you ahead.

17 O: =Oh:. Now, I understand. I just wondered < what's going on there.>

\section{Transferring learned game knowledge to a new game}

The participants played a new game (i.e., Canoeing) in the third week. This game does not require players to press any buttons. Example 4 demonstrates how the older player transferred her learned knowledge to the new game. In line 1, the younger player is telling the older player to hold the controller using both hands, without displaying the action. The older player applies what she has learned from the first game to the new one and verbally expresses her understanding of her younger partner's instruction: "Yes. A and B." She misunderstands holding both hands as pressing 'A' button and 'B' button at the same time, which is the gaming technique of the first game. The younger player immediately corrects her action by emphasizing "No buttons" and displays how to hold the controller (line 3). The older player's turn (“O:h, like this?") indicates she knows how to hold the controller so that the younger player continues to teach her how to paddle (line 5). In line 6, the older player repeatedly verbalizes her gaming actions and asks for her younger partner's feedback. The older player's repeated and continued utterances ("Go like this") and the younger player's following positive evaluation ("That is $\uparrow$ per:fect") highlights the older player's confidence in playing it. In lines 8-13, the older player initiates three continued cycles of question-answer sequences through which she adapts to the new game. The three question-answer sequences also demonstrate that the older player is able to transfer the learned game mechanisms to the new one and is able to pay attention to the key unfolding information on the screen rather than waiting for her younger partner to tell her the emerging information and what to do; however, she still needs her younger partner to confirm the actions.

\section{Example 4}

$\mathrm{O}=$ Older Player; $\mathrm{Y}=$ Younger Player

$1 \mathrm{Y}$ : So, you have to hold it with $<$ both hands $>$.

2 O: Yes. A and B.

3 Y: No buttons. We just hold it.

4. O: O:h, like this?

$5 \mathrm{Y}$ : Yeah, and I am pretty sure this is the one where you do this.

6 O: Go like this. (.) Go like this, and go like this, and go like this. Is that it?

7 Y: Yeah. That is $\uparrow$ per:fect.

8 O: Now, we have to be together or on < each side?>

9 Y: I think we have to be on each side.

10 O: Okay. Am I the blue bat there? $(0.2)<$ Or blue or?>

$11 \mathrm{Y}$ : You are the red one.

$12 \mathrm{O}: \mathrm{O}: \mathrm{h}$, where is red?

$13 \mathrm{Y}$ : This one.

\section{Negotiating game strategies and overcoming setbacks collaboratively}

With improved gaming skills, older players are able to negotiate game strategies when facing a problem. Example 5 immediately follows the ending of a game session in which the 
two players had failed a game task. In line 1, the younger player is expressing her disap-

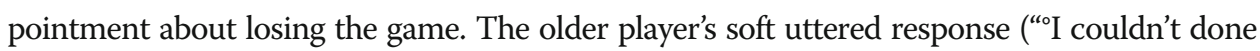
it.") indicates her disappointment with her game performance. Then, she notices the emerging information on the game screen, and asks, "What is strong arm? A type of strong arm?", which is the FPP of a question-answer sequence that directs the talk to another turntaking sequence. The younger player's response ("Strong arm and left turner") is the SPP. The older player further asks, "What does that mean? You have to have strong arms?" These two utterances display an understanding problem (or a repair initiation). In lines 6-8, the younger player explains that the on-screen information means she "had a strong arm" and the older player "turned left a lot". However, the older player misunderstands the interpretation, believing that the younger player worked very well but her left arm did not do a good job (lines 9-10). This misunderstanding is the initiator of another round of repair and the younger player's previous repair is the trouble source. The younger player immediately emphasizes "left turn" is not a bad thing, and explains it means the older player was "on the left side more than the right." To address the older player's misunderstanding, the younger player repeats the utterance, "But, that does not necessarily mean that is a bad thing." The younger player's second round of repair is effective because the older player verbalizes acceptance of her younger partner's explanation ("Okay") and thus confirms the repair. She then suggests that for the coming new game task they should be on the each side of the canoe (lines 15-16). The younger player says, "I start in the middle and then I come down right or left", indicating she respects the older player's opinion and accepts the side the older player chooses for her, but also improves the strategy by mentioning she will change the side later based on the situation. The older player accepts her younger partner's strategy and turns the talk to next sequence by asking whether they should play again. This is how the two players with different levels of game skills participate in the negotiation of game strategies and respect each other's views.

\section{Example 5}

$\mathrm{O}=$ Older Player; $\mathrm{Y}=$ Younger Player

1 Y: We were $\uparrow$ so: $\uparrow$ clo:se. Look, we are going to across the finish line. Just one second after.

2 O: ${ }^{\circ}$ I couldn't done it. ${ }^{\circ}$

3 What is strong arm? A type of strong arm?

4 Y: Strong arm and left turner. ((Trouble Source))

5 O: What does that mean? You have to have strong arms? ((Repair Initiation))

6 Y: It means that. (0.3) So, this is how we performed this time.

7 So, my blue person had a strong arm, and

8 your right person turned left a lot. ((Trouble Source))

9 O: I'm the left arm, so you are the strong arm.

10 The left arm is not doing good. ((Repair Initiation))

11 Y: I don't think that necessarily means it's bad.

12 It's just that you were probably on the left side more than the right.

13 But, that doesn't necessarily mean that is a bad thing. ((Repair Execution))

14 O: Okay. ((Repair Confirmation))

15 Well. (0.2) Wait. (10) Now, I am over here.

16 You are over here. You are rowing this way. 
17 Y: I start in the middle and then I come down right or left.

18 O: Okay. Play again?

\section{Mutual encouragement to build a common goal and shared focus}

Example 6 comes from the game session in the sixth week where the two players failed a 180-yard Canoeing task a few times. The younger player tells the older partner that they were doing "much better than last week though." The older player says, "If you say, that is good." "If you say" indicates she has no idea about their improvement because they actually had failed the game several times. In line 3, the younger player further explains, "Because I think we already passed where we were." The older player's next question ("Last week?") displays incomprehension, indicating the presence of an understanding problem. In lines 5-7, the younger player goes directly on to repairing this problem by clearly explaining how close they were to the finish line in comparison to last week. The older player's next utterance ("Yeah") is the repair confirmation, signalling the resolution of the understanding problem. In lines 9-12, the two players mutually encourage each other and build a shared goal that they will "eventually" complete the game task. In line 13, the older player changes the talk to another sequence by asking her younger partner to evaluate her action. The younger player confirms the older player's action and verbally expresses what she is doing to build shared focus (line 14). The older player continues the sequence and verbalizes her actions and goals (lines 15-16), indicating her status as a more experienced member of the game community. In line 16 , the younger player excitedly delivers the winning of the game task with rising pitch (" $€ W$ e $\uparrow$ did it! $€$ "). The older player checks, ">Did $\uparrow w e: ?<$ ", indicating she cannot believe it. The two players encourage each other to build a common goal and win the game task through coordinating and notifying each other of their actions. The older players' verbal expression of her actions and gaming goals also indicates her status as an experienced player.

\section{Example 6}

$\mathrm{O}=$ Older Player; $\mathrm{Y}=$ Younger Player

$1 \mathrm{Y}$ : We are doing much better than last week though.

2 O: If you say, that is good.

3 Y: Because I think we already passed where we were. ((Trouble Source))

4 O: Last week? ((Repair Initiation))

$5 \mathrm{Y}$ : Ye:ah and we were getting close to the line. Like last week when we were doing this 6 I was noticing that we were kind of pretty.

7 We were pretty far away from it; we were run out of time. ((Repair Execution))

8 O: Yeah. ((Repair Confirmation))

9 But at least today we are getting a little better.

10 Y: Yeah, we were like there. If it gave us one more second, we would be crossing the line.

11 O: I hope we can get there.

12 Y: Yeah, I think we will. We are so close every time. We are about to get it eventually.

13 O: I just go like this $i$

14 Y: Yeah. I am just doing like this, (0.3) kind of short.

15 O: Like from < this side to this side>. Yeah, but I go down all the time.

16 I want it to touch the water. Yeah, that is what I am doing. I want it to touch the water. 
17 Y: $£$ We $\uparrow$ did it! $€$

18 O: >Did $\uparrow$ we:?<

19 Y: $£ \uparrow Y e: a h £$

\section{Discussion}

These conversation analysis findings demonstrate that older adults start learning game mechanisms by asking questions and receiving feedback from their younger partners while responding to the game's emerging scenes and unfolding events. The younger people mentor or coach the older adults by addressing their situated questions, highlighting and correcting their mistakes, orienting their attention to the key concepts and scenes, dealing with their misunderstanding, and explaining the phenomena. It is through this situated guidance that the older adults develop game knowledge and make sense of their gaming experiences. Digital game is a goal-driven problem space in which the players develop identities when participating in emerging social practices and constructing meaning about game concepts and phenomena (Gee, 2003). As older adults build their ability to discuss game strategies, coordinate with their younger partners to overcome setbacks, and engage in mutual encouragement for a common goal, they are gradually transformed from novice players to more experienced users.

In addition, this data analysis indicates that the fundamental organization of the conversations during gameplay follows a sequential order of taking turns, which is the basic structure of the talk-in-interaction between the older adults and the undergraduates. There is no obvious overlap between two turns in the examples and in the dataset. The only exception is line 13 in the Example 2, where the older adult cannot control the fasting moving "right hand" so that she interrupts the younger player's instruction to check whether she selected her character. As can be seen in Examples 2-6, the turns are evenly distributed and no one has dominated the turns, indicating their even conversational inputs. The younger players often self-select as the next speaker when they need to take leadership, including explaining the gaming goal, notifying their partner about a new task, and commenting on their game performance. The older adults are more likely to self-select as the next speaker when they need guidance. However, they also self-select as next speaker to negotiate the game strategies as they become more experienced players (see line 15 in Example 5 and line 13 in Example 6). The younger players are selected by the older players as next speaker when they are asked for assistance or when they need to deal with the older players' misunderstanding, while the older players are selected as next speaker by the younger players to check whether they are ready for the next step or are invited by younger players to engage in interactional activities such as commenting on game performance when losing a game task (see line 1 in Example 5). The two age groups pick up on one another's turns and engage in the conversation through self-orientation and other-orientation. Conversations are purposeful and are used to accomplish social actions or goals (Chepinchikj \& Thompson, 2016). The interactional connection between the two age groups create different types of social opportunities through which the older adults develop their identities as members of the gaming community.

Furthermore, adjacency pair in the form of question-answer is a main means of situated learning. The FPP in the majority of adjacency pairs is initiated by the older adults, who ask questions when they are unable to respond to the unfolding gaming activities and scenes or need their younger partners to confirm their actions. The younger players initiate the FPP to check whether the older adults are ready for new activities. What is also 
observed in the data is that the SPP has never been delayed. Although they sometimes revise or reformulate their utterances, the younger players always offer immediate feedback or respond immediately to guide the older adults to participate in the collaborative play.

Another feature of talk-in-interaction emerged from the data is repair, which occurs when older adults misunderstand the younger players' utterances. According to the Schegloff et al. taxonomy (Levinson, 1983), the type of repair sequence found in this study is "self-initiated, other-repair" (SIOR). As shown in Examples 5 and 6, the repair is initiated by the older adults who do not understand the younger players' interpretation or comments on the game phenomena. This misunderstanding results from older adults' lack of knowledge about the concepts, rules, and game mechanisms. The younger players proceed to offer modifications or explanations of their original utterances to address the problem of understanding. Examination of the younger players' repair execution (e.g., lines 11-13 in Example 5 and lines 5-7 in Example 6) reveals that they are able to identify the type of understanding problem (e.g., rules, winning status, or information not shown on the screen) the older players face and to use appropriate repair (e.g., repeats, explanations, reformulation, facts, or concrete examples) to make their utterances more understandable to the older adults.

In this study, adjacent pair and repair are the preferred ways to organize the talk through which older adults participate in the collaborative play and construct the meaning of the game. However, the authors did not count their frequency to examine the patterns of their occurrence during the 6 weeks. It could be hypothesized that people would ask fewer questions as their gaming knowledge advanced, but this was not the case in the current study. The older players in this study could be defined as old seniors (older than 75 , on average) who suffer from physical and cognitive declines. Five of the older adults could not select characters without help from their younger partners even in the fifth week because they could not control the fast moving "right hand" and always forgot which button(s) they should press. Older adults became more experienced players by the end of the sixth week, but they still could not play the game independently and still needed to ask the younger players to confirm their actions.

\section{Conclusion}

This study used conversation analysis as a tool to examine the structures of the talk-ininteraction of naturally occurring conversations between older adults and undergraduates during 6 weeks of intergenerational digital gameplay. The features of minimum gap and overlap, even distribution of turns, and orientation to one another indicate interactional connection between the two age groups, which is the premise of the development of game communities and situated learning. Adjacency pairs in the form of question-answer and self-initiated other-repairs are the situated use of social resources afforded by the intergenerational interaction that guides older adults to participate in the collaborative play and develop understanding of unfolding concepts and phenomena. Although the findings cannot be generalized to other situations, the current study can contribute to explain the relationships between the two age groups and demonstrate how older adults can participate in collaborative activity supported by situated instruction from younger people. The findings highlight the potential of using digital games to engage older adults and younger people in meaningful interactions, which can inform better design of digital games and intergenerational programs to bridge the intergenerational gap. 


\section{Appendix A}

Table 1 Conversation analysis transcription symbols

\begin{tabular}{ll}
\hline Symbol & Meaning \\
\hline$=$ & No gap between two utterances; latching \\
$(\mathbf{0 . 0 )}$ & Timed interval (pause) in $1 / 10$ of a second \\
$()$. & A tiny gap \\
Word & Stress \\
$:$ & Sound strech \\
$:$ & Prolongation of sound \\
$?$ & Rising intonation \\
$\uparrow \downarrow$ & Shifts into higher or lower pitch \\
0 & Quieter sounds (symbol placed before and after) \\
$<>$ & Slowed down speed \\
$><$ & Speeding up \\
$\mathbf{E}$ & Smiling voice (before and after the particular words) \\
$(())$ & Descriptions, e.g. ((laughter)) \\
\hline
\end{tabular}

\section{Authors' contributions}

FZ participated in the study design, intervention, and data analysis, and drafted the manuscript. DK participated in the study design and revised the manuscript. RS participated in the study design and data coding. GS participated in the data collection and audio transcription. ETWS participated in the study design and data collection. JJ was involved in the data collection. All authors read and approved the final manuscript.

\section{Competing interests}

The authors declare that they have no competing interests.

Received: 1 December 2016 Accepted: 21 April 2017

Published online: 03 July 2017

\section{References}

Bereiter, C. (1997). Situated cognition and how to overcome it. In D. Kirshner \& J. A. Whitson (Eds.), Situated cognition: Social, semiotic, and psychological perspectives (pp. 281-300). Hillsdale: Erlbaum. Retrieved from http://www.ikit.org/ fulltext/1997situated.pdf

Black, R. W., \& Reich, S. M. (2011). Affordances and constraints of scaffolded learning in a virtual world for young children. International Journal of Game-Based Learning, 1(2), 52-64. doi:10.4018/ijgbl.2011040104

Brown, J. S., Collins, A., \& Duguid, P. (1989). Situated cognition and the culture of learning. Educational Researcher, 18(1), 32-42. doi:10.3102/0013189X018001032

Chang, D. F., \& Lin, S. P. (2011). Motivation to learn among older adults in Taiwan. Educational Gerontology, 37(7), 574592. doi:10.1080/03601271003715962

Chepinchikj, N., \& Thompson, C. (2016). Analyzing cinematic discourse using conversation analysis. Discourse, Context \& Media, 14, 40-53. doi:10.1016/j.dcm.2016.09.001

Chua, P. H., Jung, Y., Lwin, M. O., \& Theng, Y. L. (2013). Let's play together: Effects of videogame play on intergenerational perceptions among youth and elderly participants. Computers in Human Behavior, 29(6), 23032311. doi:10.1016/j.chb.2013.04.037

De Schutter, B., \& Malliet, S. (2014). The older player of digital games: A classification based on perceived need satisfaction. Communications, 39(1), 67-88. doi:10.1515/commun-2014-0005

Derboven, J., Van Gils, M., \& De Grooff, D. (2011). Designing for collaboration: a study in intergenerational social game design. Universal Access in the Information Society, 11(1), 57-65.

Entertainment Software Association (ESA). (2016). Essential facts about the computer and video game industry. Retrieved March 08, 2017 from http://essentialfacts.theesa.com/Essential-Facts-2016.pdf

Fereneík, M. (2005). Organization of repair in talk-in-interaction and politeness. Theory and Practice in English Studies, 3, 69-78

Fox, S., \& Giles, H. (1993). Accommodating intergenerational contact: A critique and theoretical model. Journal of Aging Studies, 7, 423-451. doi:10.1016/0890-4065(93)90009-9

Gee, J. P. (2008). Learning and games. In K. Salen (Ed.), The ecology of game: Connecting youth, Games, and Learning (pp. 21-40). Cambridge: The MIT Press. doi:10.1162/dmal.9780262693646.021

Gee, J. P. (Ed.). (2003). What video games have to teach us about learning and literacy. Basing-stoke: Palgrave Macmillan. 
Harley, D., Vetere, F., Fitzpatrick, G., Kurniawan, S. (2012). Intergenerational context as an emphasis for de- sign. Universal Access in the Information Society, 11(1), 1-5. doi:10.1007/s10209-011-0228-x

Hernandez, C. R., \& Gonzalez, M. Z. (2008). Effects of intergenerational interaction on aging. Educational Gerontology, 34(4), 292-305. doi:10.1080/03601270701883908

Jefferson, G. (2004). Glossary of transcript symbols with an introduction. In G. H. Lerner (Ed.), Conversation analysis: Studies from the first generation (pp. 13-31). Amsterdam: John Benjamins.

Jeske, D., \& Rosnagel, C. (2015). Learning capability and performance in later working life: Towards a contextual view. Education and Training, 57(4), 378-391. doi:10.1108/ET-08-2013-0107

Kaplan, M., Sanchez, M., Shelton, C., \& Bradley, L. (2013). Using technology to connect generations. University Park, PA: Penn State University \& Washington D.C.: Generations United. Retrieved November 12, 2016 from http://aese.psu. edu/extension/intergenerational/program-areas/technology/using-technology-to-connect-generations-report

Kern, D., Stringer, M., Fitzpatrick, G., \& Schmidt, A. (2006). Curball - A prototype tangible game for inter-generational play. In Proceedings of the Workshop on Enabling Technologies: Infrastructure for Collaborative Enterprises (pp. 412417). Manchester: IEEE Press.

Kessler, E. M., \& Staudinger, U. M. (2007). Intergenerational potential: Effects of social interaction between older adults and adolescents. Psychology and Aging, 22(4), 690-704. doi:10.1037/0882-7974.22.4.690

Khoo, E. T., Cheok, A. D., Nguyen, T. H. D., \& Pan, Z. (2008). Age invaders: Social and physical inter-generational mixed reality family entertainment. Virtual Reality, 12(1), 3-16.

Kite, M. E., Stockdale, G. D., Whitley, B. E., \& Johnson, B. T. (2005). Attitudes Toward Younger and Older Adults : An Updated Meta-Analytic Review. Journal of Social Issues, 61(2), 241-266.

Kubeck, J. E., Del, N. D., Haslet, T. K., \& McDaniel, M. A. (1996). Does job-related training performance decline with age? Psychology and Aging, 11(1), 92-107. doi:10.1037/0882-7974.11.1.92

Kun, W. (2015). Older adults' social interactions in MMORPGs. Games and Culture, 20(3), 123-130.

Lave, J., \& Wenger, E. (1991). Situated learning: Legitimate peripheral participation. Cambridge: Cambridge University Press.

Levinson, S. C. (1983). Pragmatics. Cambridge: Cambridge University Press.

Lind, C., Okell, E., \& Golab, J. (2009). Conversation analysis of repair in interaction with adults who have acquired HI. Retrieved from https://www.phonakpro.com/content/dam/phonakpro/gc_hq/en/events/2009/adult_conference_ chicago/28_P69344_Pho_Kapitel_16_S157_164.pdf

Malone, T. W. (1981). Toward a theory of intrinsically motivating instruction. Cognitive Science, 4, 333-369

Malone, T. W., \& Lepper, M. R. (1987). Making learning fun: A taxonomy of intrinsic motivation for learning. In R. E. Snow \& M. J. Farr (Eds.), Aptitude, leaning, and instruction, Volume 3: Conative and affective process analyses (pp. 223-253). Hillsdale: Erlbaum.

Manchester, H., \& Facer, K. (2015). Digital curation: Learning and legacy in later life. E-Learning and Digital Media, 12(2), 242-258. doi:10.1177/2042753014568178

Newman, S., Karip, E., \& Faux, R. B. (1995). Everyday memory function of older adults: The impact of intergenerational school volunteer programs. Educational Gerontology, 21, 569-580. doi:10.1080/0360127950210603

Ng, T. W., \& Feldman, D. C. (2008). The relationship of age to ten dimensions of job performance. The Journal of Applied Psychology, 93(2), 392-423. doi:10.1037/0021-9010.93.2.392

Padilha, E. G. (2006). Modelling turn-taking in a simulation of small group discussion. (Doctoral dissertation). Edinburgh: University of Edinburgh. Retrieved from https:/www.era.lib.ed.ac.uk/bitstream/handle/1842/1679/ Padilha\%20EG\%20thesis\%2006.pdf?sequence=1

Piirainen-Marsh, A. (2010). Bilingual practices and the social organisation of video gaming activities. Journal of Pragmatics, 42(11), 3012-3030. doi:10.1016/j.pragma.2010.04.020

Piirainen-Marsh, A., \& Tainio, L. (2009). Collaborative game-play as a site for participation and situated learning of a second language. Scandinavian Journal of Educational Research, 53(2), 167-183. doi:10.1080/0031383090275758

Reich, S. M., Korobkova, K. A., Black, R. W., \& Sumaroka, M. (2013). "Hey! Can you show me how to do this?": Digital games mediating family interactions. Retrieved from https://webfiles.uci.edu/rwblack/CB9.pdf?uniq=htjwb5

Rogoff, B. (1990). Apprenticeship in thinking: Cognitive development in social context. New York: Oxford University Press.

Rowe, J. W., \& Kahn, R. L. (1998). Successful aging. New York: Pantheon Books.

Schaie, K. W. (1994). The course of adult intellectual development. American Psychologist, 49(4), 304-313. doi:10.1037/ 0003-066X.49.4.304

Schell, R., Hausknecht, S., Zhang, F., \& Kaufman, D. (2016). Social benefits of playing Wii Bowling for older adults. Games and Culture, Special Issue: Games and Aging, 11(1-2), 81-103. doi:10.1177/1555412015607313.

United Nations. (2015). World Population Ageing 2015 Report. Retrieved March 08, 2017 from http://www.un.org/en/ development/desa/population/publications/pdf/ageing/WPA2015_Report.pdf

Vanderbeck, R. M (2007). Intergenerational Geographies: Age Relations, Segregation and Re-engagements. Geography Compass, 1(2), 200-221. doi:10.1111/j.1749-8198.2007.00012.x

Vetere, F., Nolan, M., \& Raman, R. A. (2006). Distributed hide-and-seek. In Proceedings of OZCHI'06, the CHISIG Annual Conference on Human-Computer Interaction (pp. 325-328). Sydney. https://ai2-s2-pdfs.s3.amazonaws.com/2146/ 6a30b71995c7e284326ac65935a4a109ea4c.pdf

Voida, A., \& Greenberg, S. (2012). Console gaming across generations: Exploring intergenerational interactions in collocated console gaming. Universal Access in the Information Society, 11(1), 45-56. doi:10.1007/s10209-011-0232-1

Vygotsky, L. S. (1978). Mind in society. In M. Cole, V. John-Steiner, S. Scribner, \& E. Souberman (Eds.), The development of higher psychological processes. Cambridge: Harvard University Press.

Wertsch, J. (1991). Voices of the mind: A sociocultural approach to mediated action. Cambridge: Harvard University Press.

Withnall, A. (2010). Improving learning in later life. London: Routledge.

Wouters, P., van Nimwegen, C., van Oostendorp, H., \& van der Spek, E. D. (2013). A meta-analysis of the cognitive and motivational effects of serious games. Journal of Educational Psychology, 105(2), 249-265. doi:10.1037/a0031311

Ypsilanti, A., Vivas, A. B., Räisänen, T., Viitala, M., ljäs, T., \& Ropes, D. (2014). Are serious video games something more than a game? A review on the effectiveness of serious games to facilitate intergenerational learning. Education and Information Technologies, 19(3), 515-529. doi:10.1007/s10639-014-9325-9 
Zhang, F. \& Kaufman, D. (2015). The impacts of social interactions in MMORPGs on older adults' social capital. Computers in Human Behavior, 51, 495-503. doi:10.1016/j.chb.2015.05.034

Zhang, F. \& Kaufman, D. (2016a). A review of intergenerational play for facilitating interactions and learning. Gerontechnology, 14(3), 127-138. doi:10.4017/gt.2016.14.3.002.00

Zhang, F. \& Kaufman, D. (2016b). Physical and cognitive impacts of digital games on older adults: A metaanalytic review. Journal of Applied Gerontology, 35(11), 1189-1210. doi:10.1177/0733464814566678

Submit your manuscript to a SpringerOpen ${ }^{\circ}$ journal and benefit from:

- Convenient online submission

- Rigorous peer review

- Immediate publication on acceptance

- Open access: articles freely available online

- High visibility within the field

- Retaining the copyright to your article

Submit your next manuscript at $>$ springeropen.com 